\title{
Práticas parentais e análise do comportamento: 0 estado do conhecimento de teses e dissertações de 2010 a 2015
}

\section{Parenting practices and behavior analysis: the state of knowledge of theses and dissertations from 2010 to 2015}

\section{Prácticas parentales y análisis del comportamiento: el estado del conocimiento de tesis y disertaciones de 2010 a 2015}

Taís Milena Abreu Rocha ${ }^{1}$

Paulo Roberto Holanda Gurgel ${ }^{1}$

DOI: http://dx.doi.org/10.20435/serie-estudos.v23i47.1084

\begin{abstract}
Resumo: Práticas parentais são estratégias de socialização utilizadas pelos pais em relação ao comportamento de seus filhos. Tais práticas podem ser positivas e favorecer o desenvolvimento socioemocional de crianças e adolescentes, melhorar o desempenho acadêmico e promover habilidades sociais; já práticas coercitivas podem promover problemas de comportamento e até comportamento antissocial. O objetivo deste estudo foi analisar teses e dissertações que discutem o tema práticas parentais na perspectiva da Análise do Comportamento, no período de 2010 a 2015. Os descritores utilizados na busca foram "práticas parentais" e "análise do comportamento". Entre os principais resultados, o estilo autoritativo apareceu como o estilo parental mais adequado, bem como práticas parentais como monitoria positiva e comportamento moral como as mais desejáveis ao desenvolvimento de crianças e adolescentes. A região sudeste foi a que mais produziu no período analisado (45,83\% das produções) e $50 \%$ das produções apresentaram fundamentação teórica da Análise do Comportamento de forma explícita. Lacunas foram encontradas na produção de conhecimento, como a escassez de estudos longitudinais que abordem adolescentes e jovens adultos, bem como estudos que abordem a relação entre práticas parentais e educação.
\end{abstract}

Palavras-chave: práticas parentais; análise do comportamento; estado do conhecimento.

Abstract: Parenting practices are strategies of socialization used by parents in relation to their children's behavior. Such practices can be positive and favor the socio-emotional development

${ }^{1}$ Universidade Federal da Bahia (UFBA), Salvador, Bahia, Brasil. 
of children and adolescents, improve academic performance and promote social skills; coercive practices can promote behavior problems and even antisocial behavior. The objective of this study was to analyze theses and dissertations that discuss the topic of parental practices from the perspective of Behavior Analysis, from 2010 to 2015. The descriptors used in the search were "práticas parentais" and "análise do comportamento". Among the main results, the authoritative style appeared as the most appropriate parental style, as well as parental practices such as positive monitoring and moral behavior as the most desirable to the development of children and adolescents. The Southeast region was the one that produced the most during the analyzed period (45.83\% of the productions) and 50\% of the productions presented the theoretical basis of the Behavior Analysis explicitly. Gaps have been found in the production of knowledge, such as the shortage of longitudinal studies that address adolescents and young adults, as well as studies that address the relationship between parenting practices and education.

Keywords: parenting practices; behavior analysis; state of knowledge.

Resumen: Las prácticas parentales son estrategias de socialización utilizadas por los padres en relación al comportamiento de sus hijos. Tales prácticas pueden ser positivas y favorecer el desarrollo socioemocional de niños y adolescentes, mejorar el desempeño académico y promover habilidades sociales; Ya prácticas coercitivas pueden promover problemas de comportamento e incluso comportamiento antisocial. El objetivo de este estudio fue analizar tesis y disertaciones que discuten el tema prácticas parentales en la perspectiva del Análisis del Comportamiento, en el período de 2010 a 2015. Los descriptores utilizados en la búsqueda fueron "prácticas parentales" y "análisis del comportamiento". Entre los principales resultados, el estilo autoritario apareció como el estilo parental más adecuado, así como prácticas parentales como monitoreo positivo y comportamiento moral como las más deseables para el desarrollo de niños y adolescentes. La región sudeste fue la que más produjo en el período analizado ( $45,83 \%$ de las producciones) y el $50 \%$ de las producciones presentaron fundamentación teórica del Análisis del Comportamiento de forma explícita. Se encontraron en la producción de conocimiento, como la escasez de estudios longitudinales que abordan a adolescentes y jóvenes adultos, así como estudios que aborden la relación entre prácticas parentales y educación.

Palabras clave: prácticas parentales; análisis del comportamento; estado del conocimiento.

\section{INTRODUÇÃO}

Práticas parentais são estratégias de socialização utilizadas pelos pais em relação ao comportamento de seus filhos (GOMIDE, 2003). É através da relação contexto-organismo que a criança aprende uma série de habilidades que serão úteis e se transformarão a depender das demandas sociais (ALVARENGA; PICCININI, 2009). Segundo Alvarenga e Piccinini (2001, p. 449), quando os pais orientam o comportamento de seus filhos, estão realizando a tarefa de "agentes de sua socialização" e, de acordo com tais autores, é através dessas práticas parentais

que se dá o confronto entre a criança e as regras morais da sociedade. Ainda nas palavras de Alvarenga e Piccinini (2001, p. 449): 
No convívio diário, os pais procuram direcionar o comportamento dos filhos no sentido de seguir certos princípios morais e adquirir uma ampla gama de comportamentos que garantam independência, autonomia e responsabilidade, para que mais tarde possam desempenhar adequadamente seu papel social. Por outro lado, também esforçam-se para suprimir ou reduzir comportamentos que sejam considerados socialmente inadequados ou desfavoráveis.

Práticas parentais podem ser positivas, como explicitar as consequências do comportamento da criança, expressar sentimentos positivos e negativos, expressar opiniões e estabelecer limites de forma consistente, ou negativas, como apresentar agressões verbais, agressões físicas, ameaças contingentes ou não ao comportamento da criança, disciplina relaxada, supervisão estressante ou negligência (GOMIDE, 2004; GOMIDE et al., 2005; LEME; BOLSONI-SILVA, 2010; ALVARENGA; WEBER; BOLSONI-SILVA, 2016). Somente a partir de uma análise funcional, no que tange à identificação de variáveis das quais o comportamento é função (MEYER, 2003; ULIAN, 2007), é possível estabelecer relações entre as variáveis ambientais e os comportamentos dos cuidadores e das crianças e adolescentes (LEME; BOLSONI-SILVA, 2010).

Estudos apontam que características dos pais podem favorecer ou prejudicar o desenvolvimento socioemocional de crianças e adolescentes (ALVARENGA; WEBER; BOLSONI-SILVA, 2016). Nesse sentido, práticas parentais possuem relação com o desenvolvimento de habilidades sociais, como afirmam Del Prette e Del Prette (1999), que discutem os diferentes níveis de interação que influenciam na formação do indivíduo ao longo de sua vida, apontando que a família, enquanto esfera de relações interpessoais significativas, é um dos contextos mais básicos da interação sujeito-ambiente.

A relação entre práticas parentais e desempenho acadêmico de crianças e adolescentes também é apontada na literatura (CIA; PAMPLIM; WILLIAMS, 2008; SALVADOR, 2007; FERREIRA; MARTURANO, 2002), a qual sugere o envolvimento parental nas atividades da criança, bem como a comunicação entre cuidadores e a criança como variáveis críticas para um bom desempenho acadêmico dos filhos. Hübner (1999) analisa o comportamento dos pais como um determinante do comportamento de estudar dos filhos, e descreve dois tipos de família, a pró-saber e a anti-saber. Nos termos da autora, temos:

Chamei de "pró-saber", porque as contingências e regras relativas à vida escolar de seus filhos favoreciam um clima agradável e estimulador para a 
busca do conhecimento, e aquela família "anti-saber", com contingências basicamente aversivas e regras que visavam apenas o cumprimento de tarefas e obtenção de notas. (HÜBNER, 1999, p. 252).

Alvarenga e Piccinini (2001) também discutem como as práticas parentais coercitivas são variáveis determinantes para o desenvolvimento de problemas de comportamento na criança, apontando a relação entre práticas parentais coercitivas e comportamentos externalizantes, como a desobediência, a hiperatividade e a agressividade. Ainda sobre a influência de práticas parentais coercitivas, Patterson, Reid e Dishion (2002) e Rocha (2012) estudaram a relação entre um ciclo de coerção nas relações familiares e o desenvolvimento de comportamento antissocial, que são considerados aqueles que geram estímulos aversivos para outras pessoas, como brigar, ameaçar, bater, mentir, roubar, entre outros. Segundo Gomide (2004), é de suma importância que os pais ou cuidadores estabeleçam regras e limites no convívio com seus filhos. A autora afirma que as regras precisam ser estabelecidas, não em excesso, e, principalmente, devem ser consistentes, pois, caso sejam excessivas, a chance de descumprimento é alta, e práticas parentais coercitivas entram em ação. Já se forem inconsistentes ou contraditórias, a criança aprenderá sobre o desrespeito às regras e à autoridade.

A variação da frequência e da intensidade com que os cuidadores utilizam as estratégias educacionais modulam a influência dessas práticas sobre o comportamento da criança (GOMIDE, 2003). Algumas variações de práticas parentais e combinações de diferentes práticas deram origem a estudos sobre estilos parentais que, segundo Gomide (2003), são padrões de práticas parentais mais estáveis. Alvarenga, Weber e Bolsoni-Silva (2016) afirmam que um estilo parental não é um comportamento único e linear, mas, sim, um conjunto de práticas parentais, nas quais cada estilo vai variar a partir de duas dimensões: a responsividade, que é o uso contingente de reforçadores positivos para comportamentos que favoreçam o desenvolvimento da criança ou do adolescente, e a exigência, que são uma série de comportamentos dos pais, como supervisionar, estabelecer regras claras e consistentes, definir valores morais, entre outros.

Em uma interpretação analítico-comportamental de estilos parentais, Alvarenga, Weber e Bolsoni-Silva (2016) expuseram que o estilo autoritário é caracterizado por baixa frequência de demonstração de afeto e de responsividade e alta exigência e coerção. Filhos criados nesse estilo podem desenvolver desamparo, 
comportamento internalizante e dificuldade de ajustamento com os pares. Já o estilo indulgente apresenta baixa exigência, alta responsividade e comportamento afetuoso, no qual os filhos criados nesse contexto podem ter baixa tolerância à frustração e dificuldade com autocontrole, devido à dificuldade dos pais em estabelecer regras consistentes. Pais que apresentam o estilo negligente são pouco responsivos, demonstrando pouco o afeto, e as regras e a monitoria quase não são estabelecidas na criação de seus filhos. Crianças oriundas desse estilo têm maior chance de desenvolverem comportamentos internalizantes e externalizantes ${ }^{2}$, bem como déficits nas habilidades sociais. Por fim, o estilo autoritativo é caracterizado por equilíbrio entre a responsividade e a exigência, e também entre os limites e a afetuosidade. Dessa forma, o autocontrole e a autonomia são repertórios desenvolvidos na criança, na medida em que o uso do reforçamento positivo é preferido pelos pais em detrimento de relações coercitivas.

Ao considerar possíveis contribuições da Análise do Comportamento para o tema, é importante sistematizar os esforços que têm sido feitos por pesquisas brasileiras e quais caminhos ainda precisam ser percorridos. Tendo em vista que práticas parentais são também estudadas e influenciadas pelo conhecimento científico, faz-se importante conhecer o que se tem produzido nos atuais relatórios de pesquisa do país.

Teses e Dissertações são relatórios de pesquisas que podem estabelecer importantes fontes de socialização do conhecimento produzido entre os pares da comunidade acadêmica. Parece plausível questionar sobre o que se tem produzido sobre o tema aqui abordado, na medida em que esses estudos são fontes contemporâneas de conhecimento que dão suporte às diversas práticas sobre as quais tratam. Nesse sentido, o objetivo deste estudo foi analisar Teses e Dissertações que discutem o tema práticas parentais na perspectiva da Análise do Comportamento, abarcando o período de 2010 a 2015. Este se justifica pela possibilidade de apresentar um balanço das produções, de forma a montar uma memória das pesquisas a qual possa auxiliar outros pesquisadores e profissionais interessados no tema (CHARLOT, 2006).

\footnotetext{
${ }^{2}$ Comportamentos internalizantes são caracterizados por dificuldades pessoais, como retraimento/ timidez, ansiedade e depressão. Já os externalizantes são caracterizados por impulsividade, agressão, hiperatividade, entre outros aspectos que favorecem conflitos com o ambiente (BOLSONISILVA; LOUREIRO; MARTURANO, 2016).
} 


\section{MÉTODO}

A modalidade de pesquisa chamada de estado do conhecimento trata-se de uma compreensão da produção do conhecimento sobre determinada área em um setor específico de publicações (ROMANOWSKI; ENS, 2006). Por se tratar de um panorama sobre práticas parentais na ótica da Análise do Comportamento, a partir, exclusivamente, de Teses e Dissertações, este estudo constitui-se dentro dessa proposta metodológica.

\subsection{Seleção dos dados}

O banco de dados onde foram selecionados os relatórios foi a Biblioteca Digital Brasileira de Teses e Dissertações (BDTD). Para seleção mais criteriosa do corpus de análise, foram considerados como critérios de inclusão:

I) relatórios de pesquisa que abordem o tema práticas parentais;

II) relatórios de pesquisa que se situem no período entre 2010 e 2015;

III) relatórios de pesquisa que tenham sido publicados no Brasil.

Foi considerado critério de exclusão:

I) relatórios que apresentem fundamentação teórica explicitamente distinta da Análise do Comportamento em seus resumos ou palavras-chave.

Os passos para a seleção do corpus de análise foram, portanto:

a) acessar o endereço eletrônico http://bdtd.ibict.br/vufind/;

b) selecionar "busca avançada";

c) digitar os termos "práticas parentais" e "análise do comportamento" como palavras-chave a serem buscadas;

d) refinar a busca selecionando o ano de publicação (2010 a 2015);

e) selecionar "openAccess" como tipo de acesso;

f) selecionar "português" como idioma;

g) leitura dos títulos, resumos e palavras-chave de todas as dissertações e teses apresentadas pela busca a fim de selecionar o corpus de análise.

\subsection{Mapeamento dos dados}

Após a seleção criteriosa do corpus de análise, com base nos critérios de inclusão e exclusão já descritos, foi feita a leitura integral dos relatórios de pesquisa para o mapeamento, análise e discussão dos dados, que podem ser observados a seguir. 


\section{RESULTADOS E DISCUSSÃO}

\subsection{Tipos de relatório e palavras-chave}

No período de 2010 a 2015, a busca localizou 34 relatórios em português e, após o implemento dos critérios de inclusão e exclusão, foram analisados 24 trabalhos, sendo 10 teses e 14 dissertações. Dessa maneira, como é possível notar, mais da metade dos trabalhos é composta por dissertações (Figura 1).

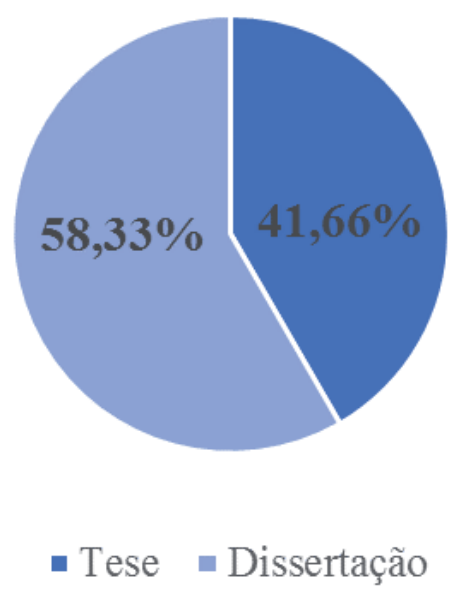

Figura 1 - Distribuição das teses e dissertações sobre práticas parentais na perspectiva da Análise do Comportamento, no período de 2010 a 2015, por tipo de relatório

Das 14 dissertações, 12 apresentaram os termos "práticas parentais" ou "práticas educativas" ${ }^{3}$ em suas palavras-chave, o que pode indicar acurácia na escoIha das palavras, além de facilitar nas buscas pelo trabalho publicado. Apenas uma tese apresentou os termos citados em suas palavras-chave. Ainda que usassem termos alusivos como "problemas de comportamento" ou "comportamento externalizante", por exemplo, ou ainda que usassem os fundamentos do Behaviorismo Radical em suas análises, de todos os trabalhos, apenas dois explicitaram o seu

\footnotetext{
3 Os trabalhos analisados utilizam os termos "práticas parentais" e "práticas educativas" como sinônimos. Entretanto, Montandon (2005) indica que prática educativa é um termo mais amplo, já que existem outros contextos educativos que não apenas o parental, como, por exemplo, a escola, a mídia, os pares etc.
} 
referencial teórico-metodológico usando "análise do comportamento" em suas palavras-chave. A hipótese é que haja baixa acurácia na escolha das palavras-chave para indicar o referencial ou baixa adesão explícita à Análise do Comportamento como fundamentação, embora os relatórios apresentem autores da área.

\subsection{Ano de publicação}

A análise da dispersão das publicações ao longo dos anos mostrou que 2013 foi o ano no qual mais se publicou sobre o tema, apresentando sete trabalhos indexados na Biblioteca Digital Brasileira de Teses e Dissertações (BDTD), totalizando $29,16 \%$ dos trabalhos. Desses sete, dois foram teses e cinco foram dissertações. Cassoni (2013), em uma revisão sistemática de artigos sobre práticas parentais, também verificou uma crescente produção de conhecimento sobre o tema a partir de 2010. Em segundo lugar, o ano de 2012 apresentou seis trabalhos (três teses e três dissertações), e os demais anos apresentaram três ou menos publicações, como se pode constatar na Figura 2 a seguir.

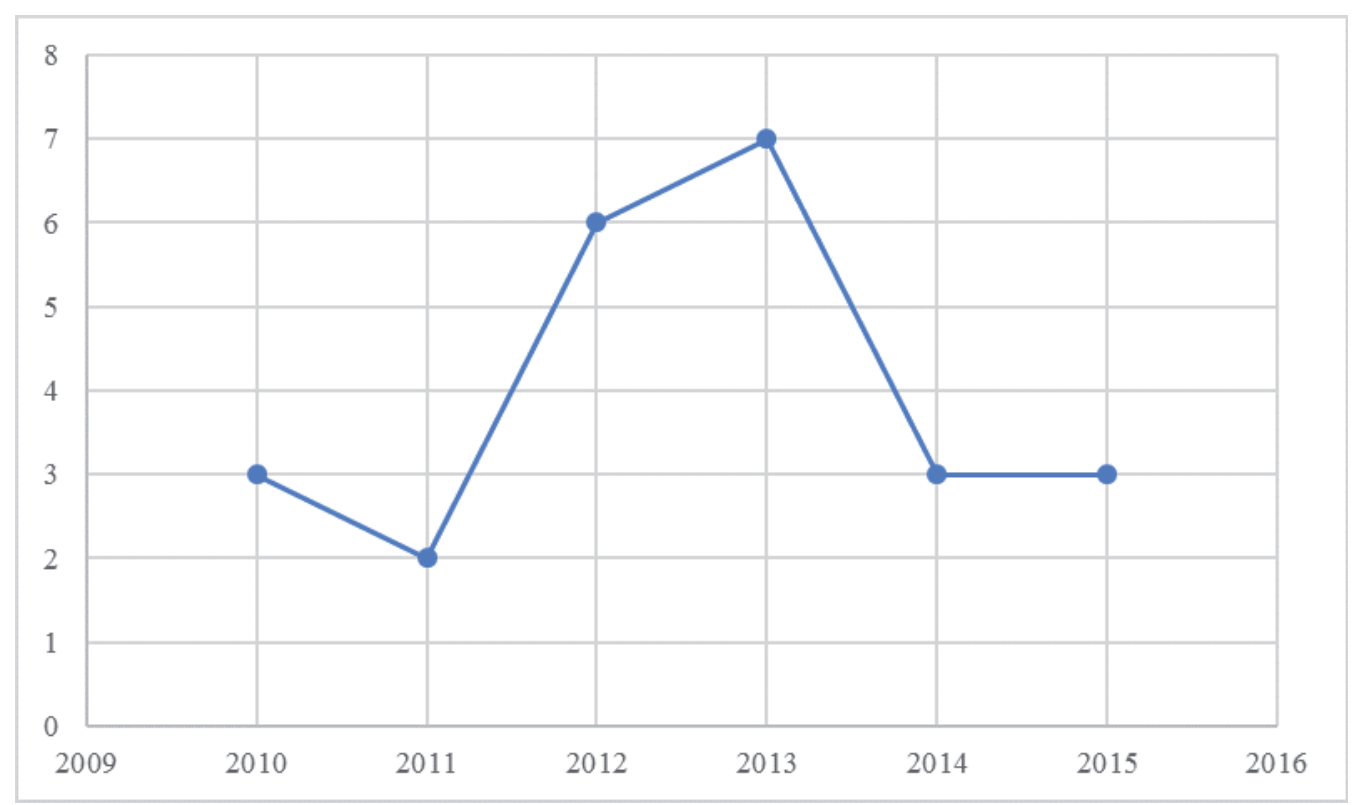

Figura 2 - Dispersão das teses e dissertações sobre práticas parentais na perspectiva da Análise do Comportamento, no período de 2010 a 2015 


\subsection{Publicações por região do Brasil}

Em relação à divisão das publicações por região do Brasil (Figura 3), observou-se um desnível na distribuição. Seis teses e cinco dissertações são da região Sudeste, totalizando 11 trabalhos, com um percentual de 45,83\% das produções. Esses dados podem indicar a região Sudeste como um polo de produção de conhecimento no país. A região Sul apresentou sete trabalhos, sendo três teses e quatro dissertações. Já as regiões Centro-oeste e Nordeste apresentaram apenas dois trabalhos cada uma e a região norte foi a menos expressiva, com apenas uma dissertação.

Há muito já se fala sobre a diferença na distribuição de recursos e investimentos científicos, que são extremamente díspares entre as regiões brasileiras. Segundo a investigação de Barros (2000), apenas 18\% dos pesquisadores existentes no Brasil são das regiões Nordeste, Centro-oeste e Norte, estando, então, nas regiões Sudeste e Sul, $82 \%$ dos grupos atuantes em pesquisa sobre o tema no país. Essa realidade pode ser evidenciada ainda hoje, seis anos depois, na presente pesquisa.

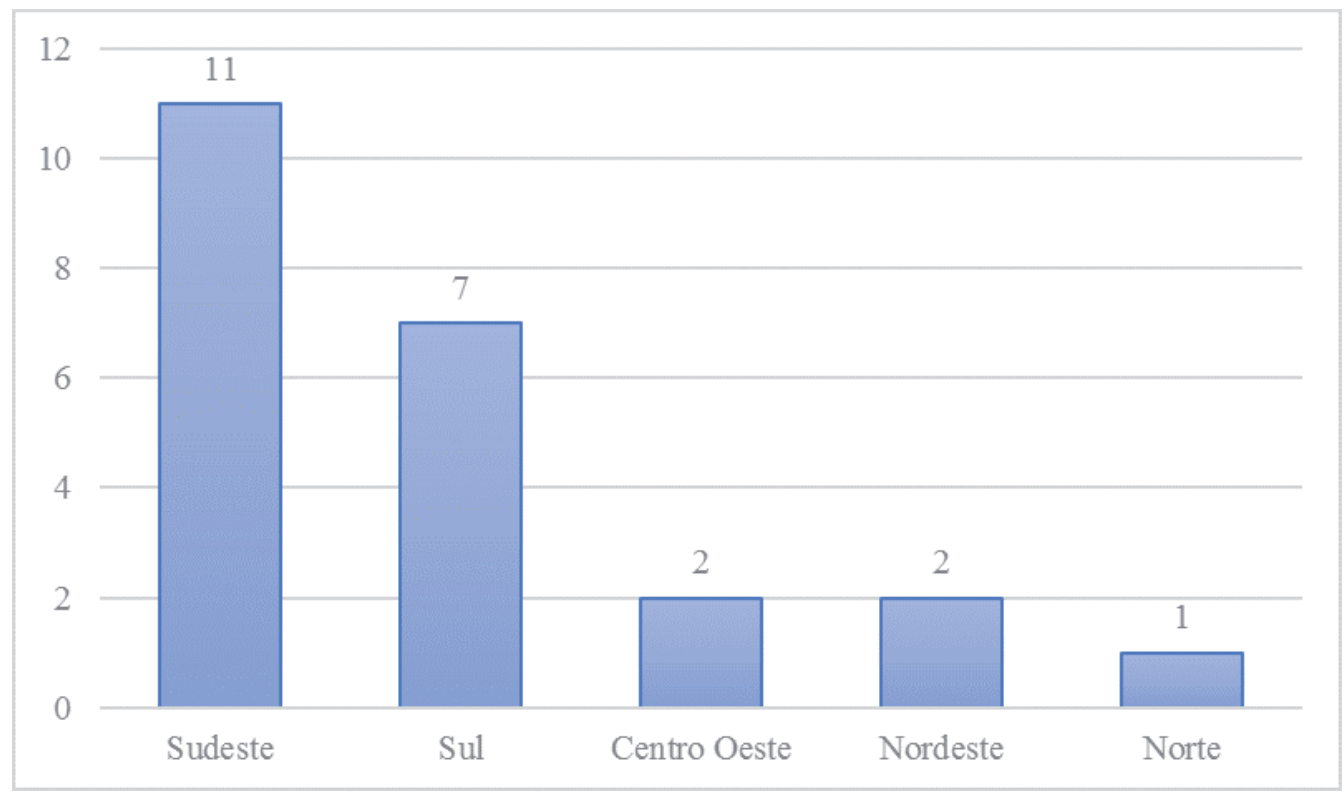

Figura 3 - Distribuição por região do Brasil de teses e dissertações sobre práticas parentais na perspectiva da Análise do Comportamento, de 2010 a 2015 


\subsection{Número de relatórios por instituição}

A Universidade de São Paulo (USP) foi a mais representativa no banco de dados analisado, pois apresentou seis trabalhos (Ribeirão Preto e São Paulo). A Universidade Estadual Paulista (UNESP) e a Universidade Federal de Santa Catarina (UFSC) apresentaram três trabalhos cada uma, e as demais instituições tiveram apenas dois ou um trabalho (Figura 4). Esses dados confirmam a hegemonia da região Sudeste na produção científica do Brasil, como também apontam Melo e Oliveira (2006), ao afirmarem que a maior parte das instituições universitárias e programas de pós-graduação encontram-se nessa região do país.

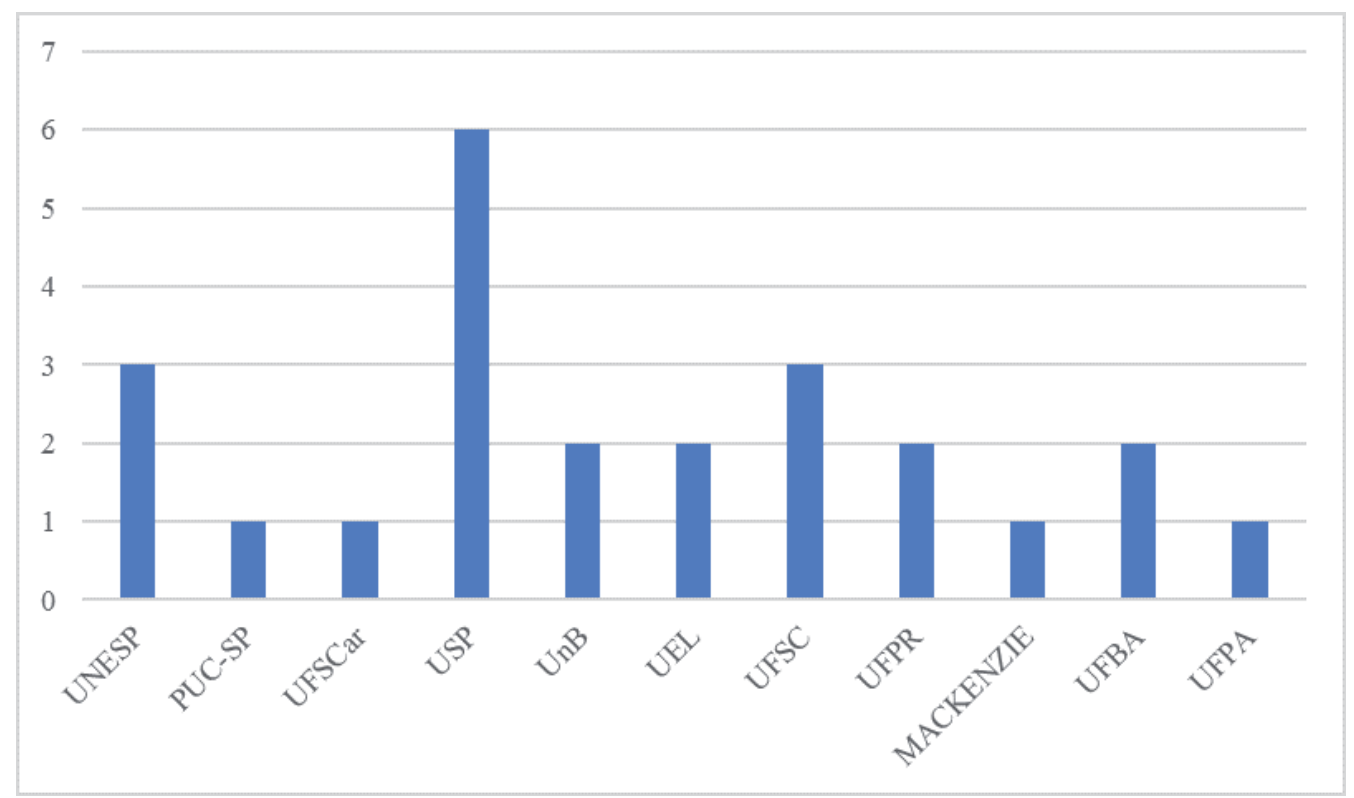

Figura 4 - Número de relatórios sobre práticas parentais na perspectiva da Análise do Comportamento, de 2010 a 2015, por instituição

\subsection{Principais conceitos de práticas parentais e autores mais frequentes}

A leitura criteriosa dos relatórios das pesquisas permitiu evidenciar os conceitos mais utilizados de práticas parentais, bem como a distinção entre práticas e estilos parentais feita por quase todos os trabalhos, além dos autores mais citados. 
Todas as 14 dissertações analisadas apresentaram o conceito de práticas parentais. De forma unânime, práticas parentais foram definidas como estratégias utilizadas pelos pais na relação com seus filhos, em que os pais objetivam promover a socialização e desenvolvimento destes por meio do controle/influência de seus comportamentos. As teses apresentaram o mesmo conceito, exceto a tese de Fortkamp (2015), que definiu um termo próximo, "parentalidade", como sendo o conjunto de processos por meio dos quais os cuidadores influenciam o desenvolvimento das crianças. Das 10 teses analisadas, cinco não trouxeram conceitos explícitos de práticas parentais (NUNES, 2010; PASIAN, 2012; BATISTA, 2013; NAVES, 2013; BOSSOLAN, 2014), seja por focarem na definição dos estilos, seja devido ao conceito de práticas parentais não ser o principal foco do trabalho.

Os trabalhos que fizeram distinção entre prática parental e estilo parental definiram estilos parentais como o conjunto mais ou menos estável de práticas. Segundo Salvo (2010), alguns autores utilizam modelos de estilos parentais mais definidos, e outros analisam cada prática parental como uma variável no desenvolvimento de comportamentos pró e antissociais, dividindo-as entre positivas e negativas, como Gomide (2003; 2004).

Alguns autores clássicos se destacaram em relação à alta frequência em que foram citados nos trabalhos (Figura 5). Baumrind (1966) aparece em 50\% dos trabalhos (12), Maccoby e Martin (1983) aparecem em 45,8\% (11), Darling e Steinberg (1993) aparecem em 33,3\% (8) e Patterson, Reid e Dishion (1992) aparecem em 25\% destes (6). Dentre os autores nacionais, destacam-se Gomide (1998; 2003; 2004; 2006) e Alvarenga e Piccinini (2001; 2007; 2009), que apareceram em 50\% e 37,5\% dos trabalhos respectivamente. Tais dados indicam que essas publicações são referências importantes quando se trata do tema práticas parentais. 


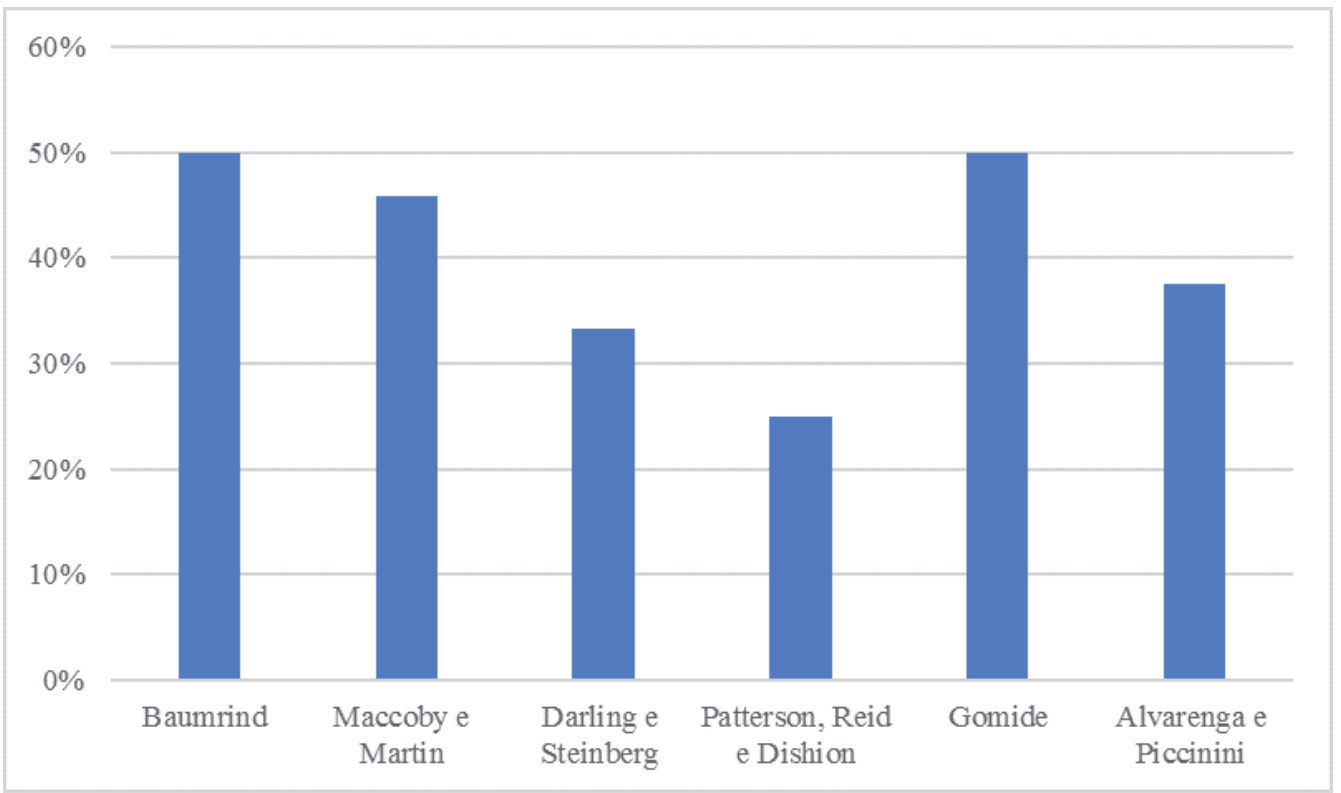

Figura 5 - Autores mais frequentes nas referências das teses e dissertações sobre práticas parentais na perspectiva da Análise do Comportamento, entre 2010 e 2015

\subsection{Contribuições da análise do comportamento}

Doze trabalhos apresentaram fundamentação teórica da Análise do Comportamento de forma explícita (SABAGG, 2010; FERNANDES, 2012; CUNHA, 2012; KAISER, 2013; OLIVEIRA, 2013; SILVA, 2013; ROVARIS, 2015; SALVO, 2010; NUNES, 2010; MESQUITA, 2012; BATISTA, 2013; NAVES, 2013), o que corresponde a $50 \%$ dos relatórios analisados. Na amostra deste estudo, o número de pesquisas que adotou explicitamente a Análise do Comportamento como fundamento é considerado inexpressivo, tendo em vista que muitos autores da área de Análise do Comportamento são utilizados na interpretação dos dados da maioria das pesquisas analisadas. Assim, o alto índice de autores da área de Análise do Comportamento pode indicar que tal abordagem tem contribuído fortemente para o estudo de práticas parentais, embora a adoção do Behaviorismo Radical enquanto filosofia explícita ainda seja baixa.

Um relatório específico merece ser evidenciado aqui como exemplo do que está sendo discutido. Barbalho (2011) discutiu sobre práticas parentais e 
desenvolvimento de crianças abrigadas, dedicando uma seção à teoria bioecológica de Bronfenbrenner, com o intuito de explicitá-la como teoria base para as análises. Entretanto os dados foram interpretados à luz de autores da Análise do Comportamento, como Gomide (2006) e Alvarenga (2001), indicando uma contradição na escolha teórica.

Foi possível observar que a Análise do Comportamento tem contribuído para o estudo das práticas parentais, inclusive de forma a apresentar uma compreensão contextualista a respeito da relação entre pais e filhos.

\subsection{Principais instrumentos}

Constatou-se que instrumentos padronizados foram utilizados com alta frequência para a coleta de dados. O Inventário de Comportamentos da Criança e Adolescente (CBCL) apareceu oito vezes, o que corresponde a 33,33\% dos trabalhos. Já o Inventário de Estilos Parentais (IEP) apareceu em seis trabalhos, o que corresponde a $25 \%$ da amostra.

O CBCL faz parte de um sistema que avalia os comportamentos infantis por faixa etária e os informantes são os pais ou cuidadores. Em geral, os itens avaliam problemas de comportamento e competência social (WIELEWICKI; GALO; GROSSI, 2011). Os autores indicam o CBCL como um dos instrumentos mais eficazes na análise das respostas parentais sobre o comportamento dos filhos.

Já o IEP é um inventário brasileiro com quarenta e duas questões que versam sobre sete práticas educativas. O informante é a criança ou o adolescente, e os itens de tal inventário revelam a percepção deste sobre as práticas parentais (SAMPAIO; GOMIDE, 2007). Ainda segundo Sampaio e Gomide (2007), cinco práticas estão relacionadas ao desenvolvimento de comportamentos antissociais - abuso físico, punição inconsistente, disciplina relaxada, monitoria negativa e negligência -, e duas práticas estão relacionadas ao desenvolvimento de comportamentos pró-sociais - monitoria positiva e comportamento moral.

\subsection{Relações feitas com desempenho acadêmico ou educação}

Tendo em vista os trabalhos analisados e a revisão de literatura feita sobre o tema, pode-se entender práticas parentais como um tipo de educação em que contingências programadas, ou não, pelos cuidadores ensinam repertórios para crianças e adolescentes. Alguns trabalhos se dedicaram a fazer uma relação clara 
entre práticas parentais e desempenho acadêmico ou comportamento de estudar, ou ainda educação de forma mais ampla.

Fernandes (2012) realizou um estudo de caso com um pai de uma criança com baixo rendimento escolar. Fora realizada intervenção de orientação sobre o comportamento de estudar e posteriormente analisou-se a influência da orientação. Com base nisso, a autora concluiu que houve mudança na interação pai-filho (uso de mais reforçadores positivos em detrimento da coerção), além de se notar menos reclamações na agenda escolar, não havendo, porém, mudanças nas baixas notas adquiridas.

Cunha (2012) analisou a influência das práticas parentais nos comportamentos acadêmicos dos filhos, a partir da avaliação do repertório de estudo de algumas gerações em cinco famílias. O autor observou que os comportamentos de estudar e supervisionar o estudo ocorrem de diferentes formas em cada família, e que a maioria delas supervisionava apenas o produto final do estudo e não o processo, no qual comportamentos inadequados das crianças eram perdidos de vista. $O$ autor concluiu que as famílias que supervisionavam o estudo utilizando reforçadores positivos, além do envolvimento com as tarefas, acabavam desenvolvendo crianças mais autônomas, isto é, que apresentavam autogoverno em relação aos estudos. Alguns padrões foram verificados, mas a pesquisa não conseguiu analisar a transmissão intergeracional de práticas de estudo. Um resultado interessante foi que apenas uma família apresentava a supervisão dos estudos feita por um homem, o que pode indicar a figura feminina ainda como a principal responsável por práticas relacionadas à educação das crianças.

Kaiser (2013) fez uma interpretação analítico-comportamental do programa Bolsa Família, analisando a frequência das crianças na escola como um pré-requisito para o reforçamento arbitrário (benefício financeiro), bem como um fator protetivo no desenvolvimento de crianças e adolescentes. Duas famílias passaram por treinamento sobre práticas parentais positivas, e tiveram como resultado a mudança do estilo parental de irregular para bom e ótimo, e ainda tiveram seus filhos de volta à escola, demonstrando a efetividade do treino.

Pasian (2012) discutiu a negligência parental e suas consequências no desenvolvimento psicossocial e acadêmico de crianças na fase inicial da escolarização. Os resultados da pesquisa com noventa mães e seus filhos indicaram que as famílias notificadas pelo Conselho Tutelar por negligência, ou as famílias 
com suspeita de maus tratos, apresentaram mais práticas parentais negligentes e mais crianças com dificuldades de aprendizagem, bem como crianças com mais chances de apresentarem dificuldades nas competências escolares e déficits no desenvolvimento no início da escolarização.

Batista (2013) apresentou um estudo inovador, buscando construir um Inventário de Estilos de Liderança de Professores (IELP) de 4ㅇ e 5 anos do Ensino Fundamental, com o objetivo de identificar os estilos presentes na relação professor-aluno, utilizando a teoria dos estilos parentais aplicada a tal relação. A autora desenvolve, aplica e avalia o IELP, concluindo que o instrumento apresenta validade interna e precisão, sendo válido, fidedigno, normatizado e de fácil aplicação.

Em síntese, os resultados corroboraram a literatura que indica a forte influência das práticas parentais sobre a construção de repertórios relacionados ao estudo e o consequente desempenho acadêmico. A responsividade, o envolvimento afetivo e o uso contingente de reforçadores positivos para comportamentos relacionados ao estudo, ou ainda o estilo parental autoritativo, são práticas consideradas adequadas e que fomentam tais repertórios (SALVADOR, 2007; D'AVILA-BACARJI; MARTURANO; ELIAS, 2005; FERREIRA; MARTURANO, 2002; HÜBNER, 1999).

\subsection{Principais resultados}

De modo geral, as pesquisas que compuseram essa amostra trataram de descrever e avaliar as influências que as práticas parentais exercem sobre os diversos repertórios de crianças e adolescentes. É possível afirmar que o estilo autoritativo foi o estilo parental apontado como o que mais promove comportamento infantil pró-social, desenvolvimento socioemocional adequado, autocontrole e autonomia, além de melhor desempenho acadêmico (SABAGG, 2010; CUNHA, 2012; KAISER, 2013; ROVARIS, 2015; SALVO, 2010; LEME, 2011; MESQUITA, 2012; entre outros). Além das práticas que caracterizam o estilo autoritativo já descrito, práticas parentais como monitoria positiva e comportamento moral apareceram também como desejáveis ao desenvolvimento de crianças e adolescentes.

Outro aspecto frequente foi o estudo de famílias em situações delicadas, consideradas de risco ao desenvolvimento das crianças, como negligência ou 
crianças em situação de abrigamento (BARBALHO, 2011; BISCOUTO, 2012; PAISAN, 2012; BOSSOLAN, 2014), baixo rendimento escolar (PASIAN, 2012; FERANDES, 2012), famílias que descumpriam as condições do Programa Bolsa Família (KAISER, 2013), habilidade social, problemas internalizantes e externalizantes (LEME, 2011; NUNES, 2012; OLIVEIRA, 2013; LINS, 2013; ROVARIS, 2015) e fatores de proteção e risco à saúde de crianças e adolescentes (SALVO, 2010; ARAÚJO, 2015). Esse dado pode indicar a relevância social das pesquisas em fornecer informações que melhorem as práticas parentais de famílias nessas situações.

\subsection{Lacunas do conhecimento}

Diante das análises feitas até aqui, foi possível identificar que nenhum trabalho analisou diretamente a influência das diferentes culturas na variação de práticas e estilos parentais (apesar da cultura ser considerada uma variável), o que nos indica uma lacuna na produção do conhecimento sobre o tema.

Sobre desempenho acadêmico ou educação, cinco trabalhos se dedicaram a tecer relações de forma mais direta entre estes e práticas parentais, o que pode indicar a necessidade de mais trabalhos nessa área, inclusive no que se refere a treinamentos de pais ou cuidadores que tenham como objetivo informar e promover práticas parentais mais efetivas.

Em relação à amostra analisada, outra possível lacuna na produção de conhecimento sobre o tema diz respeito aos efeitos das práticas parentais em adolescentes e jovens adultos. De 24, apenas dois estudos (SABAGG, 2010; SALVO, 2010) trataram dessa fase da vida. Em relação às influências mais significativas no comportamento de adolescentes, as opiniões se dividem entre o grupo de pares e da família (SHAFFER, 2005; PACHECO et al., 2005; GOMIDE, 2003). Além disso, sobretudo por não haver consenso na literatura sobre isso, observou-se a falta e a importância de estudos longitudinais que avaliem influências mais estáveis ao longo da vida.

\section{CONSIDERAÇÕES FINAIS}

A modalidade de pesquisa do presente Artigo possibilitou o conhecimento sobre a produção científica acerca do tema práticas parentais em um banco de dados específico, tomado como amostra. Foi realizado o mapeamento dessas pesquisas e foram discutidos aspectos importantes, como os principais resulta- 
dos, o aporte teórico da Análise do Comportamento, as possíveis relações entre práticas parentais e educação, entre outros.

Foi possível evidenciar a presença do corpo teórico da Análise do Comportamento e, consequentemente, de autores da área na maioria dos trabalhos analisados. Mesmo não tendo sido tomada explicitamente como principal teoria para análises, percebeu-se a forte contribuição da Análise do Comportamento.

Tendo em vista que a seleção do corpus de análise depende dos descritores utilizados na indexação dos trabalhos nos portais, foi possível identificar isso como uma limitação do método. Possivelmente, trabalhos relevantes não entraram na análise por não serem representados pelos descritores "práticas parentais" e "análise do comportamento". Para minimizar os efeitos de tal limitação, aponta-se a necessidade de mais pesquisas do tipo estado do conhecimento, e recomenda-se que seja usada maior variedade de descritores que possa abarcar, assim, outros trabalhos.

Visando contribuir para o campo teórico e para a sistematização da pesquisa acerca do tema, este estudo construiu um estado do conhecimento sobre práticas parentais e Análise do Comportamento. Espera-se colaborar com pesquisadores e profissionais da área através desse balanço, demonstrando a presença da Análise do Comportamento nas diversas áreas do conhecimento e da vida, como um campo teórico e prático das práticas parentais.

\section{REFERÊNCIAS}

ALVARENGA, P.; PICCININI, C. A. Práticas educativas maternas e indicadores do desenvolvimento social no terceiro ano de vida. Psicologia: Reflexão e Crítica, Porto Alegre, RS, v. 22, n. 2, p. 191-9, 2009.

. Práticas educativas maternas e problemas de comportamento em pré-escolares. Psicologia: Reflexão e Crítica, Porto Alegre, RS, v. 14, n. 3, p. 449-60, 2001.

ALVARENGA, P.; WEBER, L. N. D.; BOLSONI-SILVA, A. T. Cuidados parentais e desenvolvimento socioemocional na infância e na adolescência: uma perspectiva analítico-comportamental. Revista Brasileira de Terapia Comportamental e Cognitiva, São Paulo, v. XVIII, n. 1, p. 4-21, 2016.

ARAÚJO, G. S. Práticas parentais alimentares e sua relação com o consumo de alimentos na infância. 2015. 158f. Dissertação (Mestrado em Nutrição Humana) - Faculdade de Ciências da Saúde, Universidade de Brasília (UnB), Brasília, DF, 2015. 
BARBALHO, T. J. P. B. Estilos parentais em famílias de crianças abrigadas. 2011. 68f. Dissertação (Mestrado em Teoria e Pesquisa do Comportamento) - Universidade Federal do Pará (UFPA), Belém, 2011.

BARROS, F. A. F. Os desequilíbrios regionais da produção técnico-científica. São Paulo em Perspectiva, São Paulo, v. 14, n. 3, p.12-9, jul./set. 2000.

BATISTA, A. P. Construção e análise de parâmetros psicométricos do Inventário de Estilos de Liderança de Professores. 2013. 178f. Tese (Doutorado em Educação) - Universidade Federal do Paraná (UFPR), Curitiba, 2013.

BISCOUTO, K. D. Avaliação de um programa de intervenção em práticas educativas parentais para mães sociais. 2012. 151f. Dissertação (Mestrado em Análise do Comportamento) - Universidade Estadual de Londrina (UEL), Londrina, PR, 2012.

BOLSONI-SILVA, A. T.; LOUREIRO, S. R.; MARTURANO, E. M. Comportamentos internalizantes: associações com habilidades sociais, práticas educativas, recursos do ambiente familiar e depressão materna. Psico, Porto Alegre, RS, v. 47, n. 2, p. 111-20, 2016.

BOSSOLAN, R. P. História de vida, concepções sobre família, maternidade e práticas parentais de mães atendidas pelo Judiciário por denúncia de negligência materna. 2014. 120f. Tese (Doutorado em Medicina) - Universidade Estadual Paulista (UNESP), Botucatu, SP, 2014.

CASSONI, C. Estilos parentais e práticas educativas parentais: revisão sistemática e crítica da literatura. 2013. 203f. Dissertação (Mestrado em Educação) - Universidade de São Paulo (USP), São Paulo, 2013.

CHARLOT, B. A pesquisa educacional entre conhecimentos, políticas e práticas: especificidades e desafios de uma área de saber. Revista Brasileira de Educação, Rio de Janeiro, v. 11, n. 31, p. 7-18, jan./abr. 2006.

CIA, F.; PAMPLIM, R. C. O.; WILLIAMS, L. C. A. O impacto do envolvimento parental no desempenho acadêmico de crianças escolares. Psicologia em Estudo, Maringá, PR, v. 13, n. 2, p. 351-60, abr./jun. 2008.

CUNHA, R. S. M. T. Transmissão intergeracional de práticas relativas a estudo em famílias com estudantes no ensino básico. 2012. 223f. Dissertação (Mestrado em Educação Especial) - Universidade Federal de São Carlos (UFSCar), São Carlos, SP, 2012.

D'AVILA-BACARJI, K. M. G.; MARTURANO, E. M.; ELIAS, L. C. S. Suporte parental: um estudo sobre crianças com queixas escolares. Psicologia em Estudo, Maringá, PR, v. 10, n. 1, p. 43-55, jan./abr. 2005.

DEL PRETTE, Z. A. P.; DEL PRETTE, A. Psicologia das habilidades sociais: terapia e educação. Petrópolis: Vozes, 1999. 
FERNANDES, F. P. Desenvolvendo um repertório comportamental Pró Saber: estudo de caso com pais de aluno que apresenta um baixo desempenho escolar. 2012. 136f. Dissertação (Mestrado em Educação) - Pontifícia Universidade Católica de São Paulo (PUC-SP), São Paulo, 2012.

FERREIRA, M. C. T.; MARTURANO, E. M. Ambiente familiar e os problemas do comportamento apresentados por crianças com baixo desempenho escolar. Psicologia: Reflexão e Crítica, Porto Alegre, RS, v. 15, n. 1, p. 35-44, 2002.

FORTKAMP, E. H. T. Crenças e metas de socialização de pais de dois contextos urbanos brasileiros: uma análise do modelo de orientação de self. 2015. 192f. Tese (Doutorado em Psicologia) - Universidade Federal de Santa Catarina (UFSC), Florianópolis, 2015.

GOMIDE, P. I. C. Inventário de Estilos Parentais. Modelo teórico: manual de aplicação, apuração e interpretação. Petrópolis, RJ: Vozes, 2006.

. Pais presentes, pais ausentes: regras e limites. Petrópolis, RJ: Vozes, 2004.

. Estilos parentais e comportamento anti-social. In: DEL PRETTE, A.; DEL PRETTE,

Z. (Org.). Habilidades sociais, desenvolvimento e aprendizagem: questões conceituais, avaliação e intervenção. Campinas, SP: Alínea, 2003.

GOMIDE, P. I. C.; SALVO, C. G.; PINHEIRO, D. P. N.; SABBAG, G. M. Correlação entre práticas educativas, depressão, estresse e habilidades sociais. Psico-USF, São Paulo, v. 10, n. 2, p. 169-78, jul./dez. 2005.

HÜBNER, M. M. Contingências e regras familiares que minimizam problemas de estudos: a família pró-saber. In: KERBAUY, R. R.; WIELENSKA, R. C. (Org.). Sobre comportamento e cognição. Santo André, SP: Arbytes, 1999.

KAISER, F. A. Treino de habilidades parentais: estudo de caso com famílias em descumprimento de condicionalidades do programa Bolsa Família. 2013. 95f. Dissertação (Mestrado em Análise do Comportamento) - Universidade Estadual de Londrina (UEL), Londrina, PR, 2013.

LEME, V. B. R.; BOLSONI-SILVA, A. T. Habilidades sociais educativas parentais e comportamentos de pré-escolares. Estudos de Psicologia, Natal, RN, v. 15, n. 2, p. 161-73, maio/ ago. 2010.

LEME, V. B. R. Práticas parentais e recursos do ambiente de famílias nucleares, monoparentais e recasadas e o comportamento de crianças durante a transição para o ensino fundamental. 2011. 311f. Tese (Doutorado em Psicologia) - Universidade de São Paulo (USP), Ribeirão Preto, SP, 2011.

LINS, T. C. S. Práticas educativas maternas e problemas internalizantes em pré-escolares. 2013. 108f. Dissertação (Mestrado em Educação) - Universidade Federal da Bahia (UFBA), Salvador, 2013. 
MELO, H. P.; OLIVEIRA, A. B. A produção científica brasileira no feminino. Cadernos Pagu, Campinas, SP, n. 27, p. 301-31, jul./dez. 2006.

MESQUITA, M. L. G. Desenvolvimento, implementação e avaliação de um programa de treinamento parental para manejo de comportamentos de crianças e adolescentes com Síndrome de Prader-Willi. 2012. 221f. Tese (Doutorando em Distúrbios do Desenvolvimento) - Universidade Presbiteriana Mackenzie, São Paulo, 2012.

MEYER, S. B. Análise funcional do comportamento. In: COSTA, C. E.; LUIZA, J. C.; SANT'ANNA, H. H. (Org.). Primeiros passos em análise do comportamento e cognição. Santo André, SP: ESETec, 2003.

MONTANDON, C. As práticas educativas parentais e a experiência das crianças. Educação \& Sociedade, Campinas, SP, v. 26, n. 91, p. 485-507, maio/ago. 2005.

NAVES, A. R. C. X. Relações entre a mídia e leis nas mudanças da família brasileira: uma análise comportamental da evolução de práticas culturais. 2013. 198f. Tese (Doutorado em Ciências do Comportamento) - Instituto de Psicologia, Universidade de Brasília (UnB), Brasília, DF, 2013.

NUNES, C. C. Famílias de crianças em idade escolar com deficiência intelectual, dificuldades de aprendizagem ou desenvolvimento típico: comportamento, estresse materno, apoio social e percepção de impacto familiar. 2010. 122f. Tese (Doutorado em Educação) - Faculdade de Filosofia, Ciências e Letras de Ribeirão Preto, Universidade de São Paulo (USP), Ribeirão Preto, SP, 2010.

NUNES, S. A. N. Contribuições da qualidade do vínculo de apego e das práticas parentais nos problemas externalizantes e internalizantes dos filhos. 2012. 188f. Tese (Doutorado em Psicologia) - Universidade Federal de Santa Catarina (UFSC), Florianópolis, 2012.

OLIVEIRA, J. M. Efeitos de uma intervenção com foco nas práticas educativas parentais sobre os problemas internalizantes na infância. 2013. 119f. Dissertação (Mestrado em Psicologia) - Universidade Federal da Bahia (UFBA), Salvador, 2013.

PACHECO, J; ALVARENGA, P.; REPPOLD, C.; PICCININI, C. A.; HUTZ, C. S. Estabilidade do comportamento anti-social na transição da infância para a adolescência: uma perspectiva desenvolvimentista. Psicologia: Reflexão e Crítica, Porto Alegre, RS, v. 18, n. 1, p. 55-61, já./abr. 2005.

PASIAN, M. S. Maus-tratos infantis: o impacto da negligência no desenvolvimento psicossocial e acadêmico de crianças em fase inicial de escolarização. 2012. 144f. Tese (Doutorado em Educação) - Faculdade de Filosofia, Ciências e Letras de Ribeirão Preto, Universidade de São Paulo (USP), Ribeirão Preto, SP, 2012.

PATTERSON, G.; REID, J; DISHION, T. Antisocial boys: comportamento anti-social. Tradução de A. C. Lima e G. V. M. ROCHA. Supervisão técnica de P. I. C. GOMIDE. Santo André, SP: ESETec, 2002. Originalmente publicada em 1992. 
ROCHA, G. V. M. Comportamento antissocial: psicoterapia para adolescentes infratores de alto risco. Curitiba, PR: Juruá, 2012.

ROMANOWSKI, J. P.; ENS, R. T. As pesquisas denominadas do tipo "estado da arte" em educação. Revista Diálogo Educacional, Curitiba, PR, v. 6, n. 19, p. 37-50, set./dez. 2006.

ROVARIS, J. A. Análise das comparações e correlações entre problemas de comportamento, práticas parentais e habilidades sociais. 2015. 122f. Dissertação (Mestrado em Psicologia do Desenvolvimento e Aprendizagem) - Universidade Estadual Paulista (UNESP), Bauru, SP, 2015.

SABBAG, G. M. Análise das práticas e das habilidades sociais educativas maternas na interação com os filhos adolescentes. 2010. 160f. Dissertação (Mestrado em Psicologia do Desenvolvimento e Aprendizagem) - Universidade Estadual Paulista (UNESP), Bauru, SP, 2010.

SALVADOR, A. P. V. Análise da relação entre práticas educativas parentais, envolvimento com tarefas escolares, depressão e desempenho acadêmico de adolescentes. 2007. $157 f$. Dissertação (Mestrado em Educação) - Universidade Federal do Paraná (UFPR), Curitiba, 2007.

SALVO, C. G. Práticas educativas parentais e comportamentos de proteção e risco à saúde em adolescentes. 2010. 235f. Tese (Doutorado em Psicologia) - Instituto de Psicologia, Universidade de São Paulo (USP), São Paulo, 2010.

SAMPAIO, I. T A.; GOMIDE, P. I. C. Inventário de estilos parentais (IEP) - Gomide (2006): percurso de padronização e normatização. Psicologia Argumento, Curitiba, PR, v. 25, n. 48, p. 15-26, jan./mar. 2007.

SHAFFER, D. R. Psicologia do desenvolvimento. São Paulo: Thomson, 2005.

SILVA, A. L. Análise do efeito de um programa de atendimento para pais sobre a responsividade parental. 2013. 130f. Dissertação (Mestrado em Psicologia) - Instituto de Psicologia, Universidade Federal do Paraná UFPR), Curitiba, 2013.

ULIAN, AL. L. A. O. Uma sistematização da prática do terapeuta analítico-comportamental: subsídios para a formação. 2007. 240f. Tese (Doutorado em Psicologia) - Instituto de Psicologia, Universidade de São Paulo (USP), São Paulo, 2007.

WIELEWICKI, A.; GALO, A. E.; GROSSI, R. Instrumentos na prática clínica: CBCL como facilitador da análise funcional e do planejamento da intervenção. Temas em Psicologia, Ribeirão Preto, SP, v. 19, n. 2, p. 513-23, dez. 2011. 


\section{Sobre os autores:}

Taís Milena Abreu Rocha: Psicóloga pela Universidade Salvador - UNIFACS, especialista em Terapia analítico-comportamental pela UNIJORGE e mestre em Educação pela UFBA. Docente e psicoterapeuta. E-mail: ttaisabreu@hotmail.com

Paulo Roberto Holanda Gurgel: Psicólogo e licenciado em Psicologia pela Universidade Federal do Ceará; mestre em Letras (Linguística) pela Universidade Federal da Bahia e doutor em Educação (Educação: história, política e sociedade) pela Pontifícia Universidade Católica de São Paulo (2003). E-mail: pgpaulogurgel@gmail.com

Recebido em julho de 2017

Aprovado em outubro de 2017 